\title{
ACE2 Receptor-modified Algae-based Microrobot for Removal of SARS-CoV-2 in Wastewater
}

Fangyu Zhang†, Zhengxing Li†, Lu Yin, Qiangzhe Zhang, Nelly Askarinam, Rodolfo Mundaca-Uribe, Farshad Tehrani, Emil Karshalev, Weiwei Gao, Liangfang Zhang* and Joseph Wang*

Department of NanoEngineering and Chemical Engineering Program, University of California San Diego, La Jolla, CA 92093, United States.

†These authors contributed equally to this work.

*E-mail: josephwang@ucsd.edu; zhang@ucsd.edu 


\section{Materials and Methods}

Algae culture. Green C. reinhardtii algae (strain CC-125 wild-type mt+) were obtained from the Chlamydomonas Resource Center. The algae were transferred from the agar plate to tris-acetate-phosphate (TAP) medium (Thermo Fisher Scientific) and cultivated at room temperature under cycles of $12 \mathrm{~h}$ sunlight and $12 \mathrm{~h}$ dark.

Preparation of ACE2-algae-robot. Bare algae were centrifuged at $500 \times \mathrm{g}$ for $3 \mathrm{~min}$ and washed five times with ultrapure water to remove the TAP medium and then resuspended in ultrapure water. $1 \mathrm{ml}$ of $1 \times 10^{7} \mathrm{ml}^{-1}$ bare algae were treated with $20 \mu \mathrm{M}$ DBCO-PEG ${ }_{4}$-NHS ester (Click Chemistry Tools) for $1 \mathrm{~h}$ at room temperature. Here, the presence of triple bonds on the algae surface was confirmed by adding $1 \mu \mathrm{M}$ FAM azide, 5-isomer (Lumiprobe), and visualized by fluorescence microscopy. In parallel, $100 \mu \mathrm{l}$ of $73 \mu \mathrm{g} / \mathrm{ml}$ ACE2 receptor (SinoBiological) was incubated with $20 \mu \mathrm{M}$ azido$\mathrm{PEG}_{4}-\mathrm{NHS}$ ester (Click Chemistry Tools) for $1 \mathrm{~h}$ at room temperature. As prepared azido-modified ACE2 receptor was concentrated by filtration at $4000 \times \mathrm{g}$ for $10 \mathrm{~min}$ and washed three times with ultrapure water to remove free NHS ester through an ultrafilter with a $30 \mathrm{kDa}$ molecular weight cut-off (Amicon Ultra 0.5mL Filters, Sigma Aldrich); DBCO-modified algae were centrifuged at $500 \times \mathrm{g}$ for $3 \mathrm{~min}$ and washed five times with ultrapure water to remove unreacted NHS ester. The ACE2-algae-robot was fabricated by the incubation of azido-modified ACE2 receptor and DBCO-modified algae for $3 \mathrm{~h}$ via click chemistry. The resulting ACE2-algae-robots were centrifuged at $500 \times \mathrm{g}$ for 3 min and washed 3 times with TAP and collected for further studies. To fabricate the static ACE2-algae, ACE2-algae-robot was incubated with $0.01 \mathrm{M}$ PBS for $30 \mathrm{~min}$ to remove the algae flagella.

\section{Characterization of ACE2-algae-robot binding with SARS-CoV-2 pseudovirus.}

To perform scanning electron microscopy (SEM) characterization, ACE2-algae-robot binding with SARS-CoV-2 pseudovirus were fixed in $2.5 \%$ glutaraldehyde at $4{ }^{\circ} \mathrm{C}$ 
overnight and washed three times with ultrapure water before sputtering. The asprepared samples were sputtered with palladium before SEM characterization, and the SEM imaging was performed using an acceleration voltage of 3 KV (Zeiss Sigma 500 SEM instrument). The ACE2-algae-robot without SARS-CoV-2 pseudovirus was treated and examined using the same methodology. To determine the ACE2 receptor conjugation onto the algae, Fluor488-conjugated ACE2 antibody (R\&D system) was chosen to label the ACE2 receptor on the algae. The immunostaining of antibody was visualized by fluorescence microscopy (EVOS FL) with two individual fluorescence channels, Cy5 and GFP, which corresponded to the autofluorescence of algae and Fluor488-conjugated anti-ACE2 antibody, respectively. The ACE2-algae-robot, with Fluor488-conjugated anti-ACE2 antibody, was resuspended in 1\% BSA in PBS for flow cytometry analysis. Data were acquired with a BD FACSCanto II flow cytometer and analyzed using the FlowJo software.

Motion analysis of ACE2-algae-robot. The motion of ACE2-algae-robot, dibenzocyclooctyne (DBCO) modified algae and bare algae were analyzed in different media: tris-acetate-phosphate medium (TAP), $0.1 \times$ phosphate-buffered saline (PBS; diluted from $1 \times$ PBS with DI water), drinking water from Arrowhead Springs, river water from Peñasquitos Creek. After transferring to the drinking water or river water containing SARS-CoV-2 spike protein or pseudovirus, the speed of ACE2-algae-robot was evaluated at $0 \mathrm{~h}, 1 \mathrm{~h}, 4 \mathrm{~h}, 12 \mathrm{~h}$, and $24 \mathrm{~h}$. The movies of the motion were captured by an inverted optical microscope (Nikon Eclipse Instrument Inc. Ti-S/L 100) coupled with different microscope objectives $(4 \mathrm{x}, 10 \mathrm{x}$, and 20x), a Hamamatsu digital camera C11440, and NIS Elements AR 3.2 software. An NIS Element tracking module was used to measure the corresponding algae speed in different media.

Cell culture. Human bronchial epithelial non-tumoral cell line NL-20 (CLR-2503, American Type Culture Collection, ATCC) was cultured in HAM-F12 medium (Invitrogen) supplemented with $2.7 \mathrm{~g} / \mathrm{L}$ glucose (Gibco), 4\% fetal bovine serum (FBS), $0.1 \mathrm{mM}$ non-essential amino acids (Gibco), $5 \mu \mathrm{g} / \mathrm{ml}$ of insulin (Sigma Aldrich), 10 $\mathrm{ng} / \mathrm{ml}$ of epidermal growth factor (Sigma Aldrich), $1 \mu \mathrm{g} / \mathrm{ml}$ of transferrin (Sigma 
Aldrich), $500 \mathrm{ng} / \mathrm{ml}$ of hydrocortisone (Sigma Aldrich), 1\% penicillin/streptomycin (Gibco) at $37^{\circ} \mathrm{C}$ in a $5 \% \mathrm{CO}_{2}$ environment. The cells were detached from culture flasks using $1 \times$ PBS containing $13.7 \mu \mathrm{L}$ of $0.5 \mathrm{M}$ ethylenediaminetetraacetic acid (EDTA) and $5 \%$ fetal bovine serum (FBS) at $37^{\circ} \mathrm{C}$ and collected with centrifugation at $700 \times \mathrm{g}$ for $5 \mathrm{~min}$ for further study.

Removal of SARS-CoV-2 spike protein. To explore the effect of ACE2-algae-robot density on the efficiency of spike protein removal, ACE2-algae-robot was incubated with $500 \mu \mathrm{l} 2.88 \mathrm{ng} / \mathrm{ml}$ spike protein with different algae density of $5 \times 10^{7} \mathrm{ml}^{-1}, 2 \times$ $10^{7} \mathrm{ml}^{-1}$, and $5 \times 10^{6} \mathrm{ml}^{-1}$ in drinking water and tested the removal efficiency at $0 \mathrm{~h}, 1$ h, $2 \mathrm{~h}, 4 \mathrm{~h}, 6 \mathrm{~h}$, and $16 \mathrm{~h}$. To explore the kinetic profiles of spike protein removal efficiency in drinking water, the bare algae, static ACE2-algae, and cell-wall deficient algae with a density of $5 \times 10^{7} \mathrm{ml}^{-1}$ were incubated with $500 \mu 12.88 \mathrm{ng} / \mathrm{ml}$ spike protein. $5 \times 10^{7} \mathrm{ml}^{-1}$ ACE2-algae-robot were also incubated with $500 \mu 12.88 \mathrm{ng} / \mathrm{ml}$ spike protein in different media, including DI water, drinking water, and river water, to study the environmental effect on the removal efficiency. To measure the spike protein removal efficiency, all the groups were centrifuged at $500 \times \mathrm{g}$ for $3 \mathrm{~min}$ and quantified by SARSCoV-2 spike RBD protein ELISA kits (ABclonal).

Removal of SARS-CoV-2 pseudovirus. To explore the effect of ACE2-algae-robot density on SARS-CoV-2 pseudovirus removal efficiency, ACE2-algae-robot was incubated with $50 \mu 12 \times 10^{9} \mathrm{VG} / \mathrm{ml}$ SARS-CoV-2 pseudovirus (Montana Molecular) with different algae density of $5 \times 10^{4} \mathrm{ml}^{-1}, 5 \times 10^{5} \mathrm{ml}^{-1}, 5 \times 10^{6} \mathrm{ml}^{-1}$, and $5 \times 10^{7} \mathrm{ml}^{-1}$ in drinking water for $16 \mathrm{~h}$. To explore the kinetic profiles of SARS-CoV-2 pseudovirus removal efficiency in drinking water, the bare algae, static ACE2-algae and cell-wall deficient algae with a density of $5 \times 10^{6} \mathrm{ml}^{-1}$ were incubated with the same amount of SARS-CoV-2 pseudovirus for $16 \mathrm{~h}$. To explore the time dependence removal efficiency of SARS-CoV-2 pseudovirus in drinking water, $5 \times 10^{6} \mathrm{ml}^{-1}$ ACE2-algae-robot was incubated with the same amount of SARS-CoV-2 pseudovirus in drinking water at room temperature for $0 \mathrm{~h}, 1 \mathrm{~h}, 2 \mathrm{~h}, 4 \mathrm{~h}, 6 \mathrm{~h}, 16 \mathrm{~h}$, the bare algae and static ACE2-algae were treated with the same method. The method of reusability of ACE2-algae-robot 
was studied as before. For the post-treatment, $5 \times 10^{6} \mathrm{ml}^{-1}$ ACE2-algae-robots were treated by $0.5 \%$ chitosan for $10 \mathrm{~min}$. In comparison, the control groups were treated by $500 \times \mathrm{g}$ centrifugation for $3 \mathrm{~min}$. Before measuring SARS-CoV-2 pseudovirus removal efficiency, 15,000 NL-20 cells per well were seeded in a 96-well plate for $24 \mathrm{~h}$ at $37^{\circ} \mathrm{C}$ in a $5 \% \mathrm{CO}_{2}$ environment, and then the supernatant with unbound SARS-CoV-2 pseudovirus from each sample was incubated with the cells for $24 \mathrm{~h}$. The fluorescence intensity of the mixture was analyzed by fluorescence microscopy and quantified using a BioTek Synergy Mx microplate reader. 


\section{Supplementary Figures}

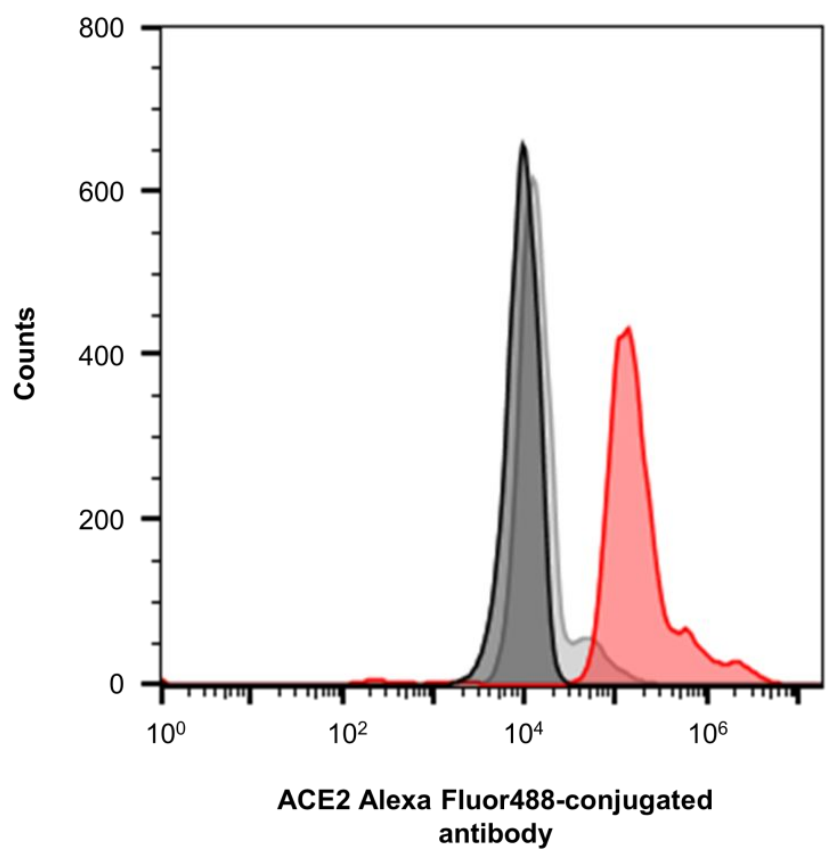

Figure S1. Flow cytometry histograms of bare algae (black), bare algae with Fluor488conjugated anti-ACE2 antibody (grey), and ACE2-algae-robot with Fluor488conjugated anti-ACE2 antibody (red). The shift of the flow cytometry histogram demonstrates that ACE2 receptors are conjugated to the algae surface. 

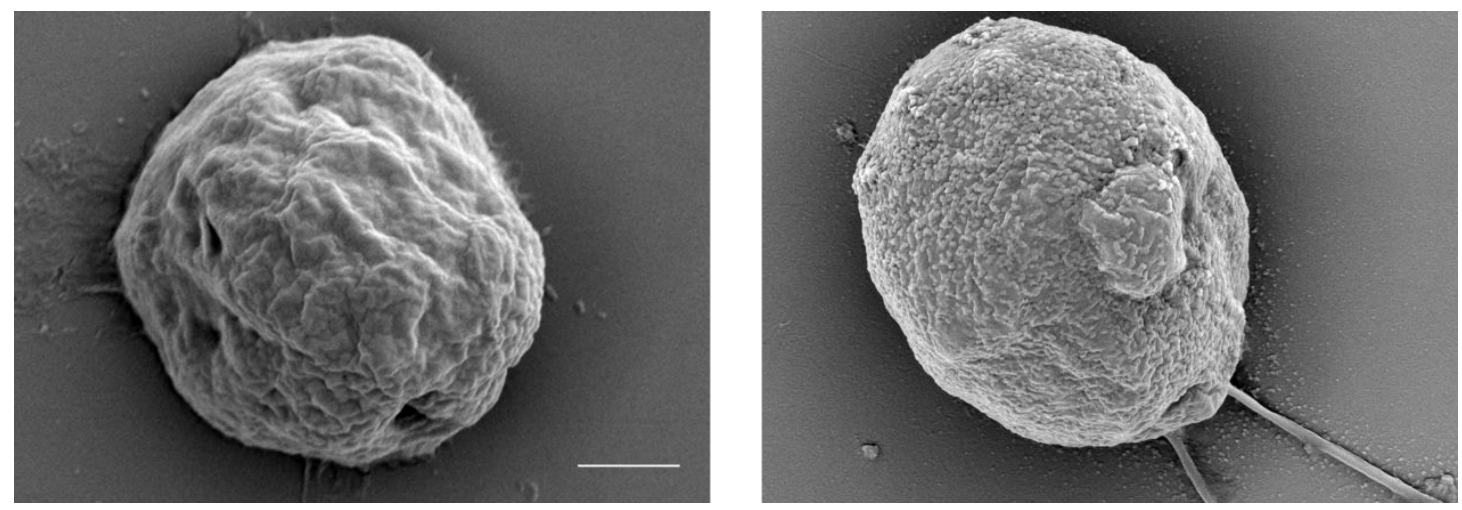

Figure S2. SEM images of ACE2-algae-robot before (left) and after (right) contact with SARS-CoV-2 pseudovirus. The pseudovirus bound ACE2-algae-robot (right) displayed rough surface with binding of small pseudovirus nanoparticles compared to the bare ACE2-algae-robot (left) with a relative smooth surface, without binding of pseudovirus nanoparticles. Scale bar: $2 \mu \mathrm{m}$. 

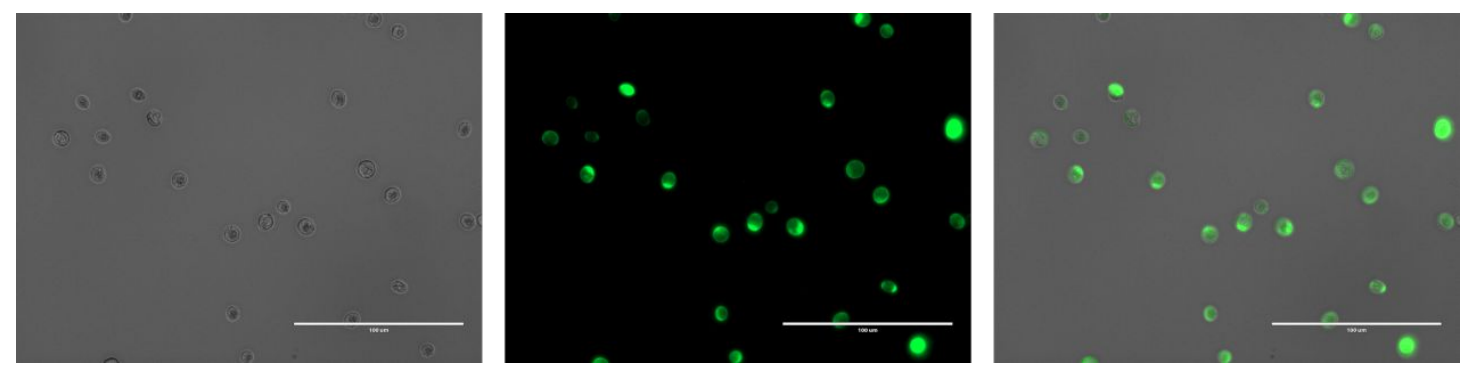

Figure S3. Representative microscopy brightfield and fluorescence images of bare algae incubated with $\mathrm{DBCO}-\mathrm{PEG}_{4}-\mathrm{NHS}$ ester and labeled with an azido-based fluorescence probe. The superimposed green color on the algae surface indicates conjugation of DBCO-PEG 4 -NHS ester to the algae surface via NHS-amine reaction. the Scale bar: $100 \mu \mathrm{m}$ 

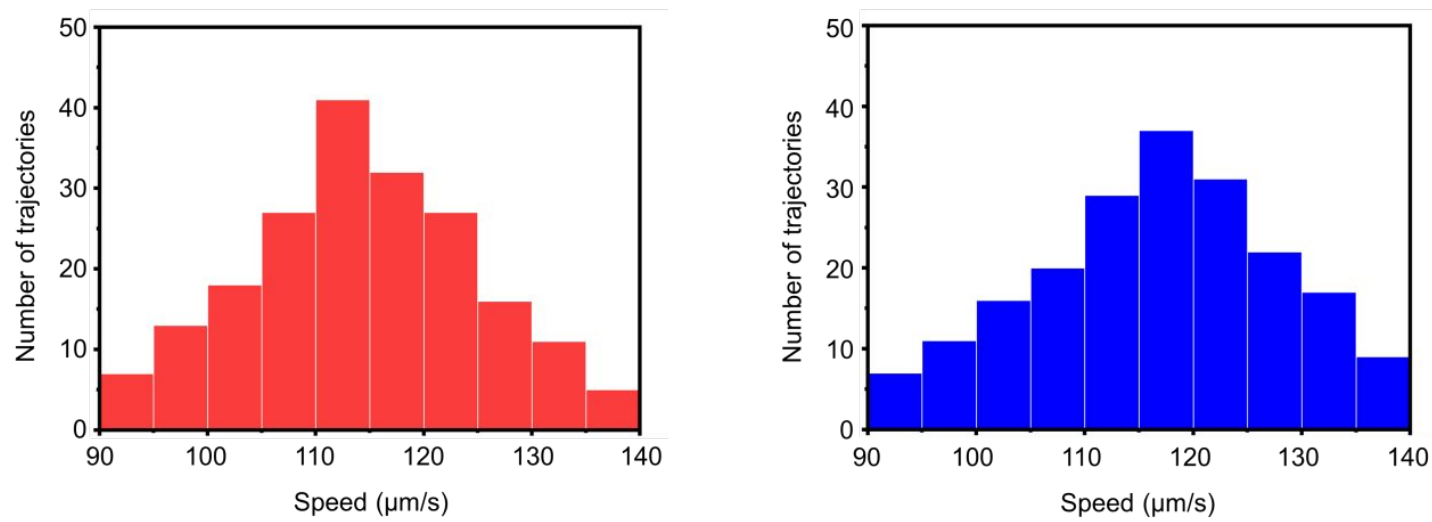

Figure S4. Mean speed distribution of ACE2-algae-robot in drinking water (red) and river water (blue) containing SARS-CoV-2 spike protein. 


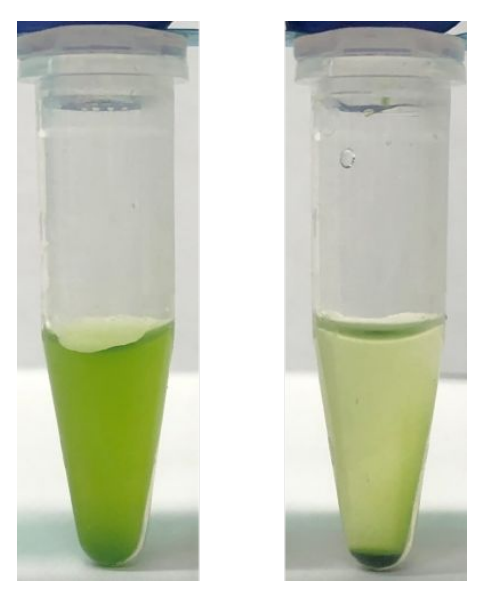

Figure S5. Photographs of ACE-algae-robot (left) and static ACE2-algae (right) after $6 \mathrm{~h}$ incubation with SARS-CoV-2 spike protein in drinking water. The ACE2-algaerobot sample showed a homogenous mixture due to the constant motion of the robot. In comparison, static ACE2-algae sank within hours and deposited to the bottom of the Eppendorf tube. 


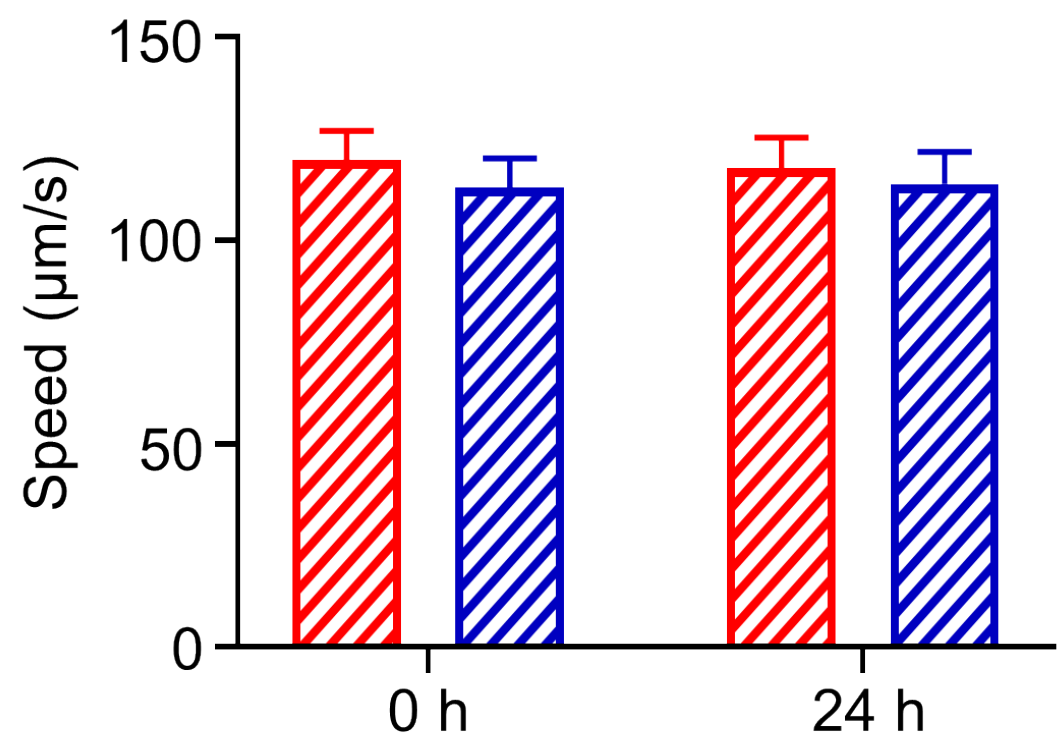

Figure S6. Speed comparison of ACE2-algae-robots before and after $24 \mathrm{~h}$ motion in drinking water (red) and river water (blue) containing SARS-CoV-2 pseudovirus. The negligible speed change after $24 \mathrm{~h}$ motion in these aqueous media indicates that the presence of the pseudovirus does not affect the movement of ACE2-algae-robot. 


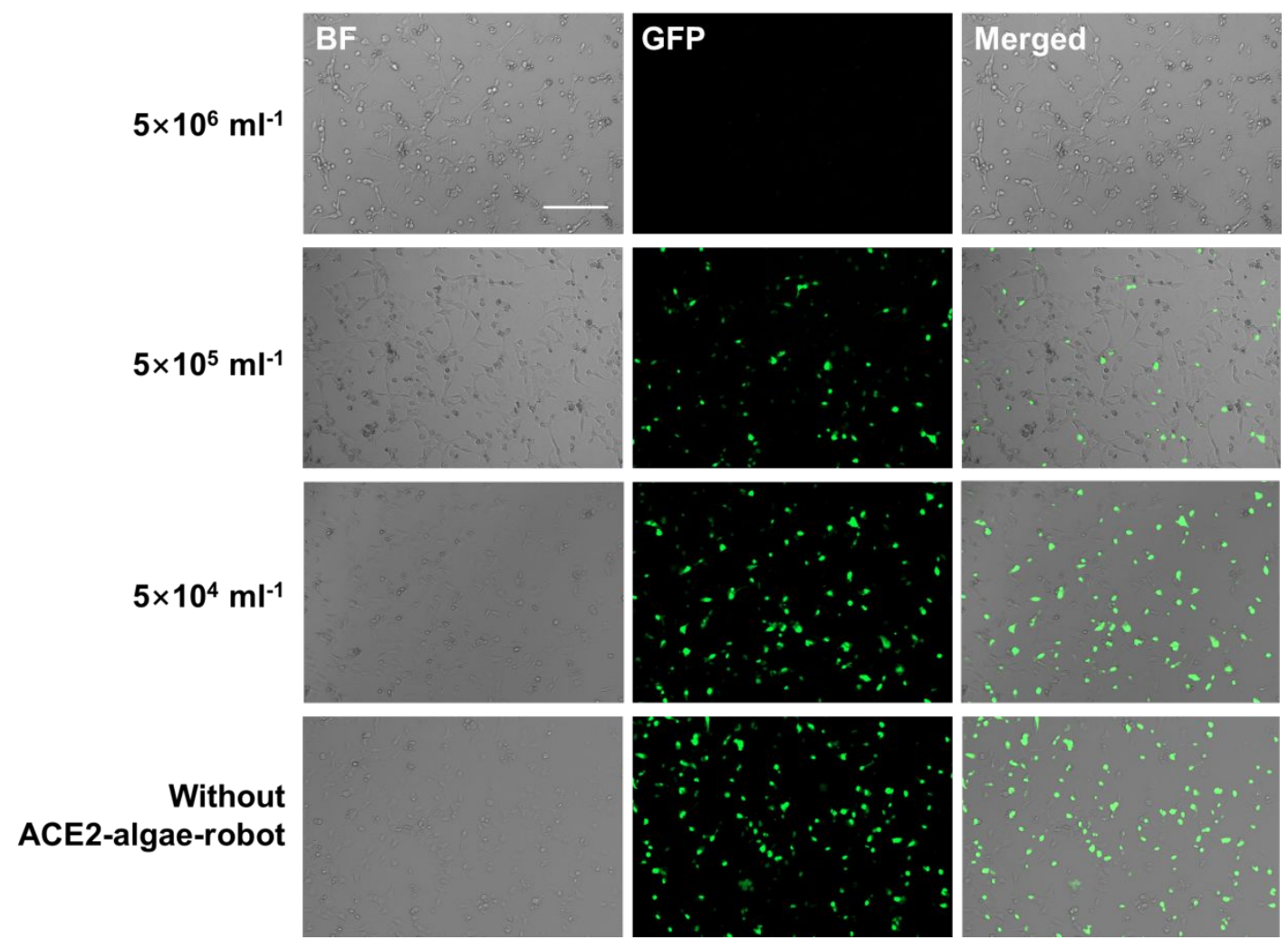

Figure S7. Representative microscopy brightfield and fluorescence images of NL-20 cells infected with virus treated by different densities of ACE2-algae-robot. Scale bar: $100 \mu \mathrm{m}$ 


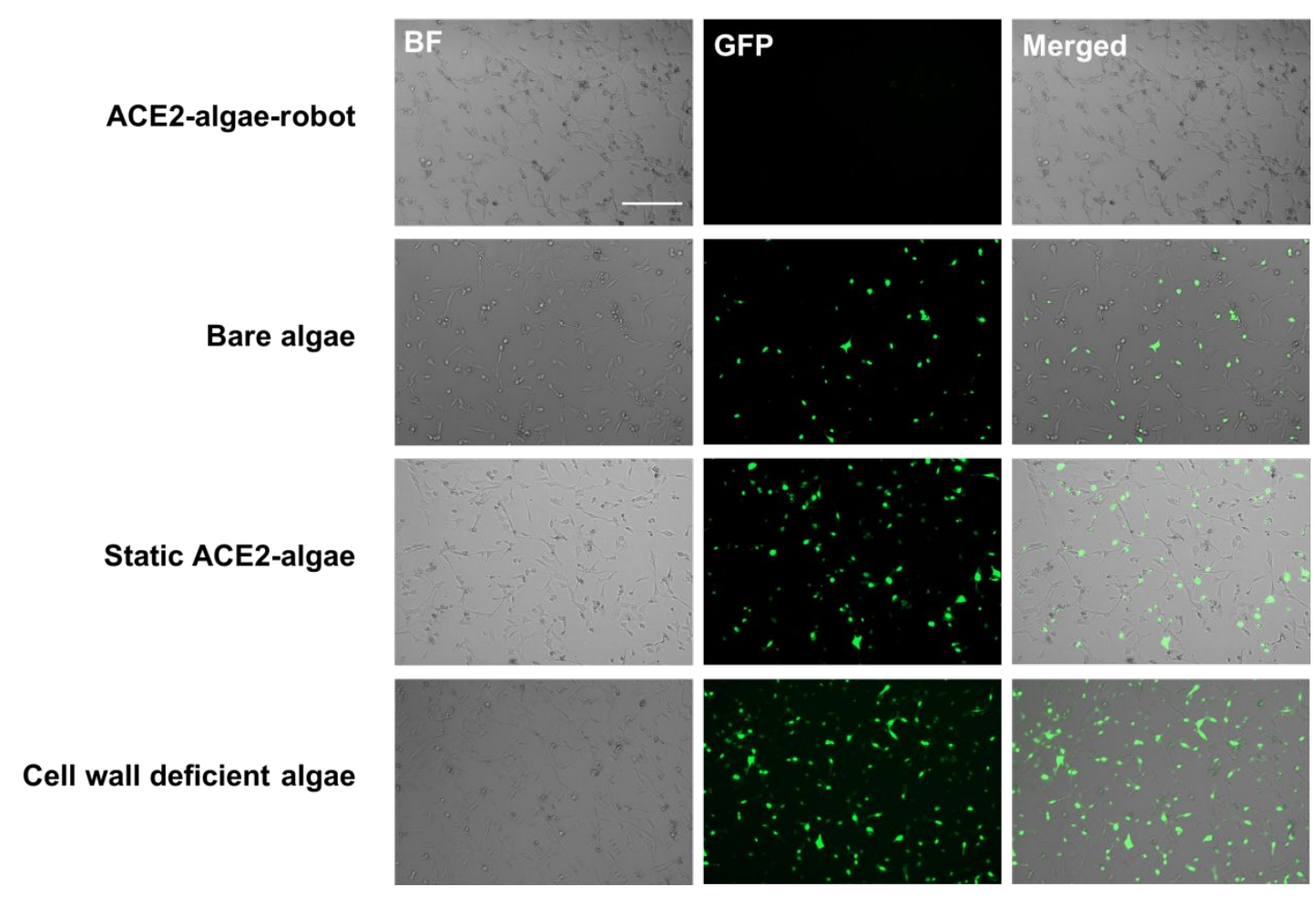

Figure S8. Representative microscopy brightfield and fluorescence images of NL-20 cells infected with virus treated by ACE2-algae-robot, bare algae, static ACE2-algae, and cell-wall deficient algae. Scale bar: $100 \mu \mathrm{m}$ 

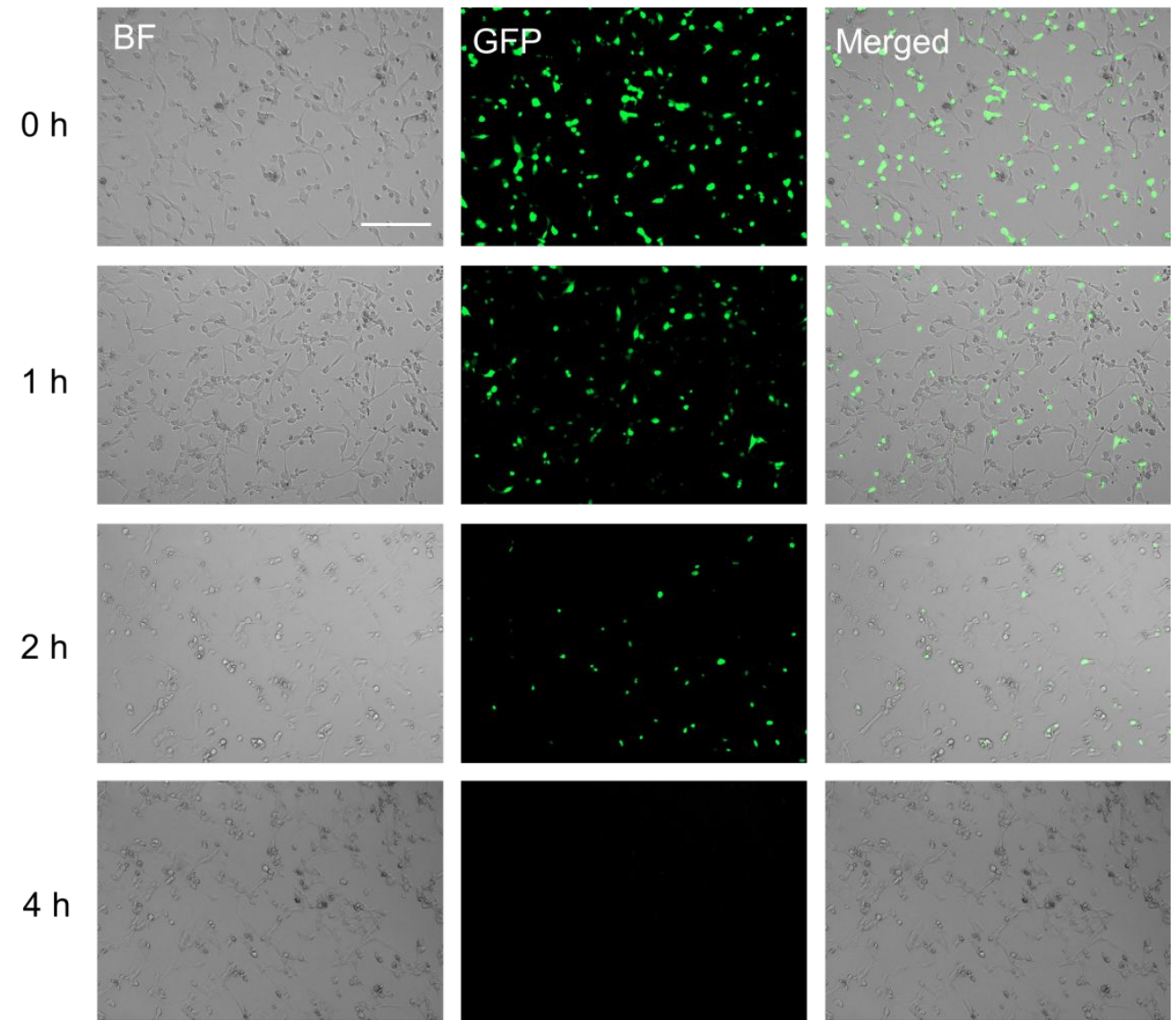

Figure S9. Representative microscopy brightfield and fluorescence images of NL-20 cells infected with virus treated by ACE2-algae-robot for different times $(0 \mathrm{~h}, 1 \mathrm{~h}, 2 \mathrm{~h}$, and 4 h). Scale bar: $100 \mu \mathrm{m}$. 


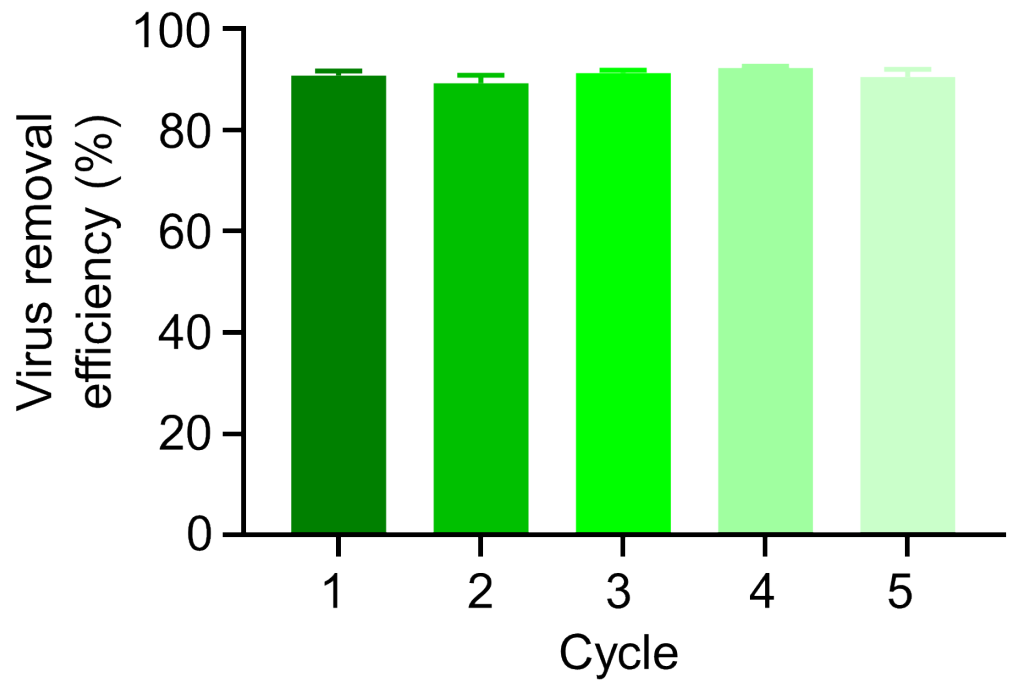

Figure S10. Efficiency of virus removal after ACE2-algae-robot reutilization. $(n=3$; mean + s.d.). 


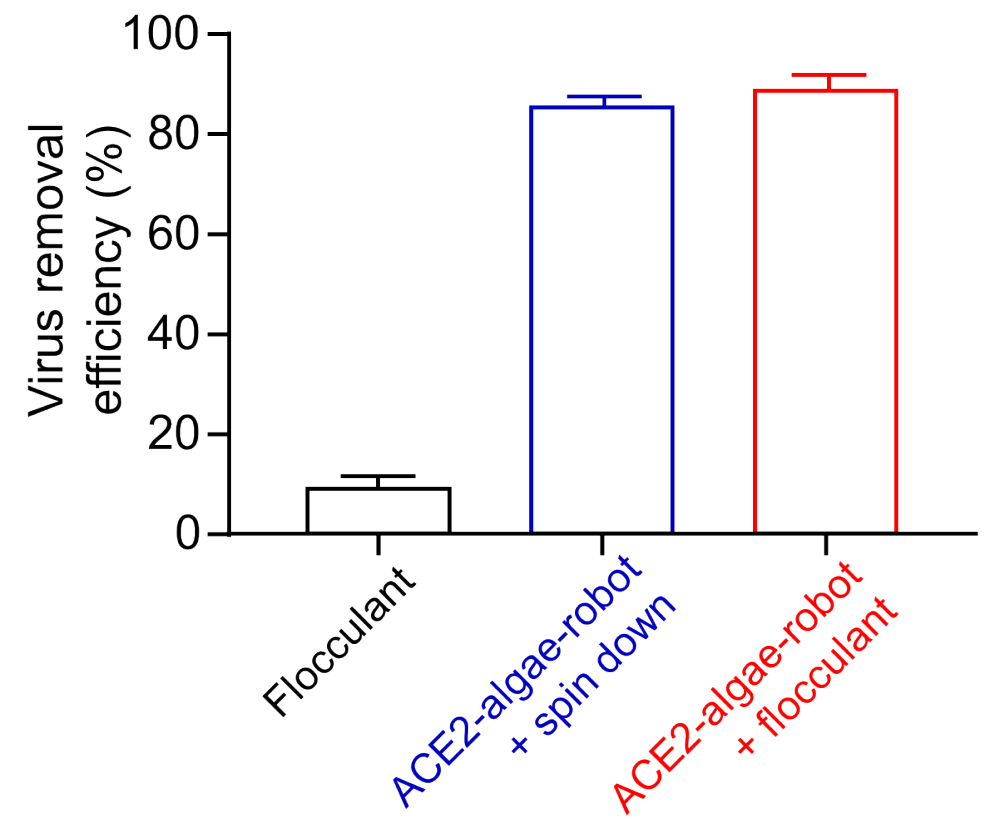

Figure S11. Efficiency of the virus removal from drinking water after employing ACE2-algae-robot with post-treatment by flocculant. $(\mathrm{n}=3$; mean + s.d. $)$. After flocculation of ACE2-algae-robot, the efficiency of virus removal can reach $\sim 90 \%$ comparable to that of the sample treated by laboratory-based algae separation method $(87 \%)$. 


\section{Supplementary Movies}

Movie S1. Effect of the algae functionalization upon its swimming behavior.

Movie S2. Motion of the ACE2-algae-robot in different aqueous media.

Movie S3. Speed of ACE2-algae-robot at different time points in drinking water and river water

Movie S4. Representative optical trajectories of the movement of ACE2-algae-robot over $2.5 \mathrm{~s}$ motion in drinking water

Movie S5. Representative optical trajectories of the movement of ACE2-algae-robot over $2.5 \mathrm{~s}$ motion in river water 